\title{
Trajectories of physical function prior to death and brain neuropathology in a community-based cohort: the act study
}

\author{
Andrea Z. LaCroix ${ }^{1,2^{*}}$ (D, Rebecca A. Hubbard ${ }^{3}$, Shelly L. Gray ${ }^{4}$, Melissa L. Anderson ${ }^{2}$, Paul K. Crane ${ }^{4}$,
} Joshua A. Sonnen ${ }^{5}$, Oleg Zaslavsky ${ }^{6}$ and Eric B. Larson ${ }^{2}$

\begin{abstract}
Background: Mechanisms linking cognitive and physical functioning in older adults are unclear. We sought to determine whether brain pathological changes relate to the level or rate of physical performance decline.

Methods: This study analyzed data from 305 participants in the autopsy subcohort of the prospective Adult Changes in Thought (ACT) study. Participants were aged 65+ and free of dementia at enrollment. Physical performance was measured at baseline and every two years using the Short Physical Performance Battery (SPPB). Data from 3174 ACT participants with $\geq 2$ SPPB measurements were used to estimate two physical function measures: 1) rate of SPPB decline defined by intercept and slope; and 2) estimated SPPB 5 years prior to death. Neuropathology findings at autopsy included neurofibrillary tangles (Braak stage), neuritic plaques (CERAD level), presence of amyloid angiopathy, microinfarcts, cystic infarcts, and Lewy bodies. Associations (adjusted for sex, age, body mass index and education) between dichotomized neuropathologic outcomes and SPPB measures were estimated using modified Poisson regression with inverse probability weights (IPW) estimated via Generalized Estimating Equations (GEE). Relative risks for the $20^{\text {th }}, 40^{\text {th }}$, and $60^{\text {th }}$ percentiles (lowest levels and highest rates of decline) relative to the 80th percentile (highest level and lowest rate of decline) were calculated.
\end{abstract}

Results: Decedents with the least vs. most SPPB decline (slope $>75^{\text {th }}$ vs. $<25^{\text {th }}$ percentiles) had higher SPPB scores, and were more likely to be male, older, have higher education, and exercise regularly at baseline. No significant associations were observed between neuropathology findings and rate of SPPB decline. Lower predicted SPPB scores 5 years prior to death were associated with higher risk of microinfarcts (RR $=3.08,95 \%$ confidence interval $(\mathrm{Cl}) 0.93-1.07$ for the $20^{\text {th }} \mathrm{vs}$. $80^{\text {th }}$ percentiles of SPPB) and significantly higher risk of cystic infarcts (RR $=2.72,95 \% \mathrm{Cl} 1.45-5.57$ for $20^{\text {th }}$ vs. $80^{\text {th }}$ percentiles of SPPB).

Conclusion: Cystic infarcts and microinfarcts, but not neuropathology findings of Alzheimer's disease, were related to physical performance levels five years before death. No pathology findings were associated with rates of physical performance decline. Physical function levels in the years prior to death may be affected by vascular brain pathologies.

Keywords: Physical function, Functional decline, Brain neuropathology, Alzheimer's disease, Vascular dementia

\footnotetext{
* Correspondence: alacroix@ucsd.edu

${ }^{1}$ Division of Epidemiology, Department of Family Medicine and Public

Health, University of California San Diego, 9500 Gilman Drive, La Jolla, CA

92093, USA

${ }^{2}$ Kaiser Permanente Washington Health Research Institute, 1730 Minor

Avenue, Suite 1600, Seattle, WA 98101, USA

Full list of author information is available at the end of the article
} 


\section{Background}

The US population of adults aged 65 and older has multiplied over 12-fold since 1900 reaching 40.3 million in 2010, and is projected to more than double again to 83.7 million by 2050 [1]. Mortality rates continue to decline among those aged 65 and older, but older Americans place a higher value on remaining in good health and being able to take care of themselves than they do on longevity [2]. The prevalence of disability in older Americans is estimated at 38\% [1] including physical, cognitive, sensory, and self-care disabilities. Thus, identifying the causes of functional declines and effective interventions to reverse these losses is extremely salient for older adults, and a major societal concern.

Evidence emerging over the last decade suggests that cognitive and physical function are linked [3] but the temporal nature of declines in each domain and underlying mechanisms are poorly understood. Older adults rely on more regions of their brain for movement than younger people [4]. Lower grip strength and gait speed have been associated with markers of brain aging including brain atrophy and white matter hyperintensities [5]. However, the role of brain pathology in driving declines in physical function is virtually unknown. Frailty is a composite construct including weakness, slowness, low physical activity, weight loss and fatigue. When frailty is measured shortly before death it has been associated with pathology related to Alzheimer's Disease [6]. Moreover, the rate of change in frailty over a 6-year period has been associated with multiple brain neuropathologies including macroinfarcts, Alzheimer's Disease (AD) and Lewy body pathology, and nigral neuronal loss [7]. However, other studies of frailty and incident dementia have shown associations between frailty and non-AD but not AD dementia [8-10]. In the Adults Changes in Thought (ACT) study, physical function [11] and frailty [10] both predicted onset of dementia, but it is not known whether these associations were related to brain neuropathologies indicative of $\mathrm{AD}$ or non-AD dementia or both.

The objective of this analysis was to test the hypothesis that trajectories of physical function and physical function prior to death were associated with neuropathologic findings typical of $\mathrm{AD}$ or vascular dementia among participants in the ACT study who died and consented to autopsy.

\section{Methods}

\section{Study population}

ACT recruits community-dwelling, non-demented adults age 65 and older from among Group Health
$(\mathrm{GH})$ members living in or near Seattle, Washington. The original cohort of 2581 people was enrolled between 1994 and 6 and an expansion cohort $(n=811)$ was enrolled between 2000 and 2002. In 2004, the study began ongoing enrollment to replace people who die or drop out. In all phases, potential participants were randomly selected from eligible GH members. A total of 4415 participants had been enrolled at the time of this analysis.

Models used to characterize physical performance trajectories are based on the subset of 3174 individuals with at least two Short Physical Performance Battery [12, 13] measurements (Fig. 1). Dementia status at the time of death is an important predictor for selection into the autopsy cohort (individuals who died and came to autopsy), therefore selection models used to estimate and adjust for the probability of inclusion in the autopsy sample exclude people whose dementia status at the time of death was not known. The subset of 305 individuals who died and came to autopsy were included in analyses of neuropathologic outcomes (Fig. 1).

\section{Physical performance}

Physical performance was measured at baseline, and every two years during study follow-up. The ACT SPPB protocol was based on a validated, composite measure of objective physical performance that included: the ability to stand with feet together in the side-by-side, semi-tandem, and tandem positions (i.e. balance), $10 \mathrm{ft}$ timed walk, and the time to rise from a chair and return to the seated position 5 times. Each item (balance, gait speed, and chair stands) is scored on a $0-4$ scale, and summed to define a composite score with a range of $0-12$, with higher scores indicating higher function [12, 13]. We used linear mixed effects models to estimate subject-specific slopes and intercepts, which were used to describe SPPB trajectories. We estimated trajectories of SPPB for all ACT participants with at least two nonmissing SPPB scores, rather than limiting to the ubsample with neuropathology data, so that the distribution of slopes and intercepts estimated by the random effects model would reflect the distribution among the population of older adults more generally. For deceased ACT participants for whom neuropathology data were available, we computed the predicted SPPB five years prior to death based on the participant's age at death and the slope and intercept estimated from his or her SPPB data. The estimated subject-specific slopes and SPPB five years prior to death were the primary exposure measures. 


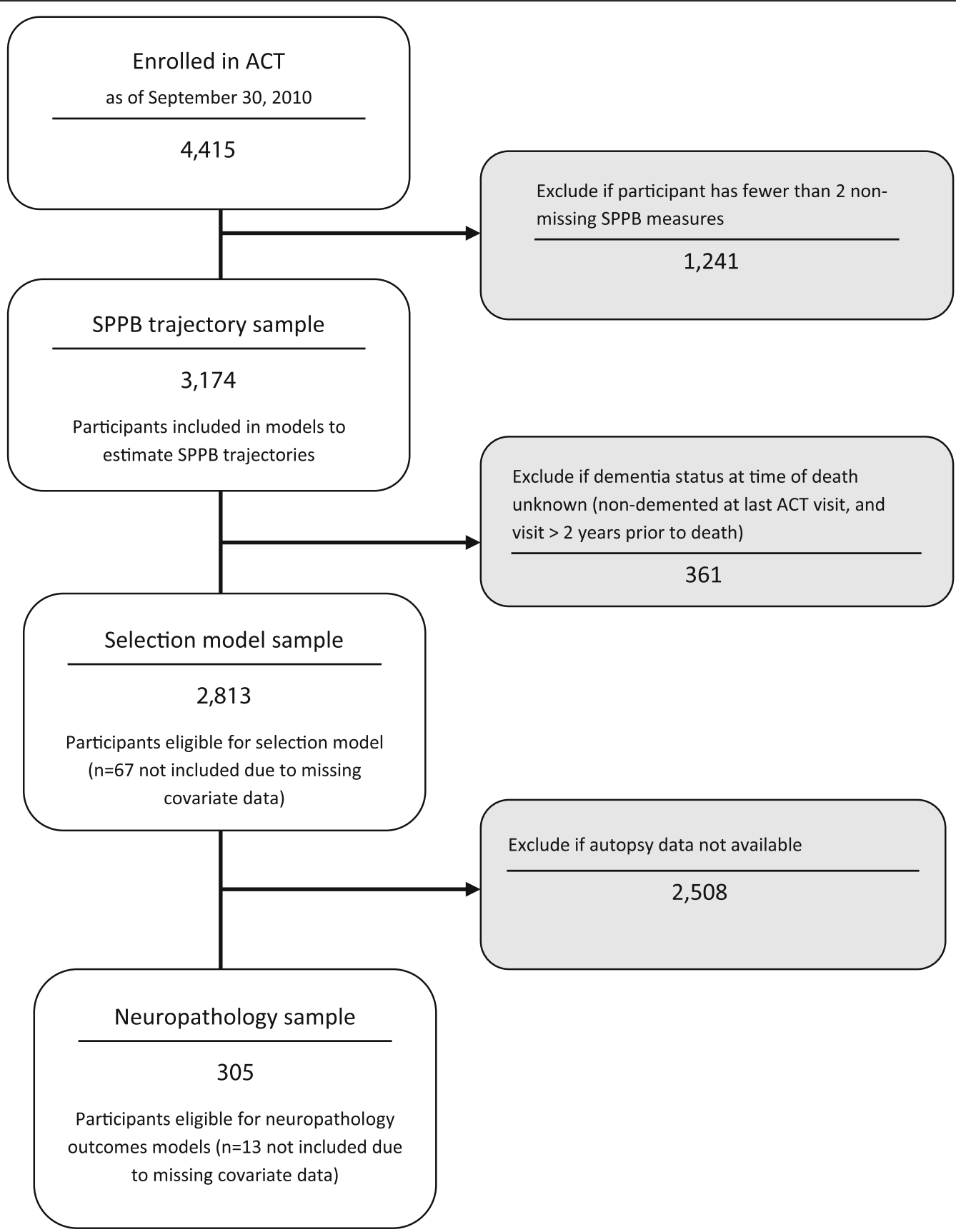

Fig. 1 Flow diagram of ACT participants and autopsy subcohort with neuropathological measurements

\section{Outcomes}

Neuropathologic assessments were performed and dichotomized at the level previously associated with dementia $[14,15]$ by board certified neuropathologists at the Alzheimer 's disease Research Center, Neuropathology Core in the Department of Pathology at the University of Washington. Changes indicative of $\mathrm{AD}$ (neuritic plaques assessed by Consortium to Establish a Registry for Alzheimer's Disease staging criteria $[16,17]$, neurofibrillary tangles assessed by Braak staging [18, 19], and amyloid angiopathy [20]), cerebrovascular disease (cerebral microinfarcts, macroscopic infarcts, and atherosclerosis), Lewy bodies, and hippocampal sclerosis [21, 22] were assessed. Details 
have been published ([23] see eMethods 5). Briefly, for Alzheimer pathology, functional dichotomization identified neuritic plaques by the presence of six or more neuritic plaques identified by Bielschowsky sliver staining in a single high powered field of middle frontal gyrus or inferior parietal lobule, neurofibrillary tangles pathology was dichotomized by the presence of tangles in all field of the hippocampus and entorhinal cortex as well as association cortex by tau immunohistochemistry, and amyloid angiopathy was dichotomized by the presence of circumferential amyloid staining by Congo red histochemistry in a screening section of cortex. For vascular pathology, cystic infarcts were identified at the time of gross examination and confirmed as chronic infarcts by histology while microinfarcts pathology was dichotomized as positive if two or more were identified at the time of histologic exam as chronic infarcts but not identified as chronic infarcts. Hippocampal sclerosis was defined present is there was complete loss of neurons within the CA1 field of the hippocampus with or without involvement of the subiculum. Lewy bodies were classified as present when identified by immunohistochemistry for alpha-synuclein in a section of the frontal cortex. Corticol Lewy body indices were obtained but were too infrequent to be included in the analysis. No measurements of long-tract white matter disease are currently available.

\section{Covariates}

Demographic characteristics including age, sex, educational attainment, and study cohort were collected at baseline. Study participants reported smoking status, and regular exercise (defined as $15 \mathrm{~min}$ or more at least 3 times per week), and body mass index (BMI) was calculated based on measured height and weight at baseline and each follow-up visit. Grip strength was measured as part of the physical performance assessment at baseline and study follow-up visits. Methods for diagnosing dementia in ACT have been previously reported [24]. Briefly, participants complete cognitive screening at biennial study visits, and those with low scores are referred for further evaluation with a clinical examination and a neuropsychological battery. All data are then reviewed by a consensus committee that assigns dementia diagnoses based on the Diagnostic and Statistical Manual of Mental Disorders, $4^{\text {th }}$ Edition (DSM-IV).

\section{Statistical analysis}

Descriptive counts and percentages for covariates were computed for dichotomized neuropathologic outcomes by quartiles of estimated subject-specific SPPB slopes.
The quartiles were defined based on the distribution of SPPB trajectories in the autopsy cohort.

Analyses of the association between dichotomized neuropathologic outcomes and characteristics of SPPB trajectories were conducted using modified Poisson regression with inverse probability weights (IPW) estimated via Generalized Estimating Equations (GEE). Modified Poisson regression allowed us to estimate relative risks of more severe neuropathology outcomes rather than odds ratios, which are more common but difficult to interpret in the case of binary outcomes [25]. IPW were used to account for the selection mechanisms resulting in inclusion in our autopsy cohort. By including these weights we were able to estimate associations between neuropathology and SPPB trajectories that are generalizable to the ACT cohort as a whole. Selection models used to compute the weights included terms for sex, race, education, ACT cohort, and characteristics measured at last study follow-up visit including dementia status, exercise, smoking, and BMI. Neuropathology outcome models were adjusted for sex, education, and age and BMI measured at the last study follow-up visit. We obtained confidence intervals and $p$-values for neuropathology outcome models via bootstrap sampling to account for uncertainty in the selection model as well as the neuropathology outcome model. We used a bias-corrected and accelerated bootstrap procedure [26] with 1000 samples from the bootstrap distribution to estimate the sampling distribution of model parameters.

Each neuropathology outcome was evaluated in separate models testing each of two predictors describing the SPPB trajectory: the subject-specific slope of SPPB and the predicted SPPB five years prior to death. Natural cubic splines with two degrees of freedom were used to describe associations between these predictors and the log-risk of an adverse neuropathologic outcome. Splines were used to model these associations to avoid imposing assumptions about the functional form of relationships between characteristics of the SPPB trajectory and risk of adverse neuropathologic outcomes. Relative risks (RR) were computed for the $20^{\text {th }}, 40^{\text {th }}$, and $60^{\text {th }}$ percentiles of the distribution of SPPB slope and SPPB five years prior to death relative to the $80^{\text {th }}$ percentile. Plots of the RR curves were created to visualize risk relative to the $80^{\text {th }}$ percentile of the SPPB slope and predicted SPPB five years prior to death distributions for a continuous range of values. $P$-values were computed based on Wald tests for estimated relative risk at the $20^{\text {th }}, 40^{\text {th }}$, and $60^{\text {th }}$ percentiles of SPPB slope or predicted SPPB five years prior to death relative to the 80th percentile. 
Statistical significance was evaluated using alpha $=0.05$. All statistical analyses were conducted using R 2.15.1.

\section{Results}

\section{Estimation of SPPB trajectories}

Among the 3174 participants included in the estimation of physical performance trajectories, the mean number of SPPB measures was 4.2 (standard deviation 1.9 ), and the range was 2 to 9 measures (23\% had 2, $22 \%$ had 3 , and $55 \%$ had 4 or more measurements of SPPB). Estimated SPPB trajectories revealed substantial variation in change in physical performance with age. Compared to the quartile with the steepest decline (SPPB slope $<-0.256$ per year) shown in black (Fig. 2), the quartile of decedents with the least decline (SPPB slope $>-0.148$ per year), had higher SPPB scores at baseline on average, had a higher proportion of men (57.9\%), had higher average educational attainment, had a higher proportion who regularly exercised, were older on average, and had faster gait speeds at baseline on average (Table 1). There were no apparent differences in classification of dementia or AD at last ACT study visit by quartile of SPPB slope. For comparison, characteristics of the cohort of 2813 participants, stratified by estimated slope of the SPPB trajectory, are provided in Table 5 in Appendix. Although not identi-

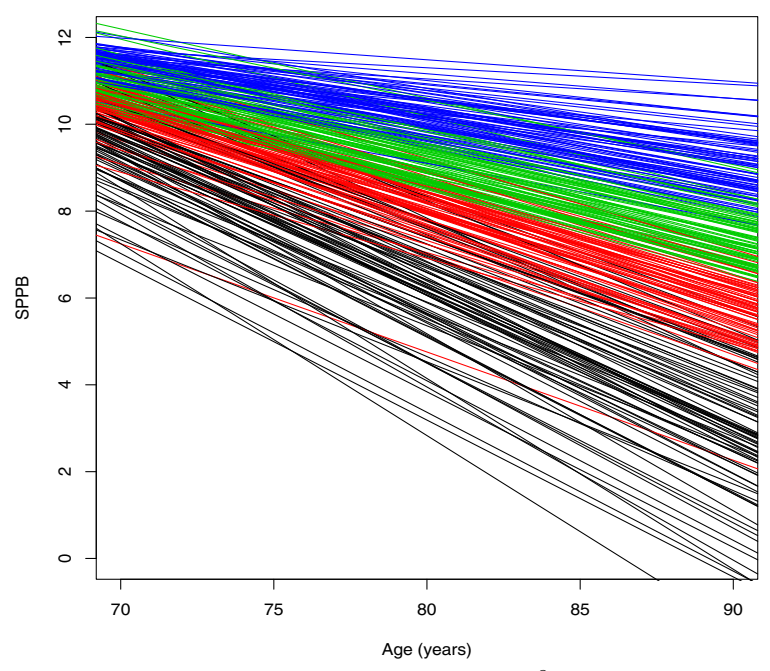

Fig. 2 Estimated subject-specific SPPB trajectories ${ }^{\text {a }}$ for 305 autopsied ACT participants. 'Lines are color coded by quartile of slope. Black = $>75^{\text {th }}$ percentile, $R e d=50^{\text {th }}-75^{\text {th }}$ percentile, Green $=25^{\text {th }}-50^{\text {th }}$ percentile, Blue $=<25^{\text {th }}$ percentile. $75^{\text {th }}$ percentile $=-0.148,50^{\text {th }}$ percentile $=-0.196,25^{\text {th }}$ percentile $=-0.256$ cal to the associations observed among decedents, many of the patterns described above are similar in the larger cohort.

\section{Associations of SPPB trajectories with Neuropathologic findings at autopsy}

Unadjusted distributions of CERAD (neuritic plaques), Braak (neurofibrillary tangles) and amyloid angiopathy neuropathology classifications revealed no orderly pattern across quartiles of SPPB slope, while microinfarcts and cystic infarcts appeared more common among decedents with the fastest SPPB declines (Table 2). After adjustment for sex, age, BMI and education, no statistically significant associations were seen for plaques or tangles, but relative risks were in the direction of lower risk of these neuropathologies among autopsied decedents who had steeper declines in SPPB prior to death (Table 3). Risk of amyloid angiopathy was significantly lower among decedents with the fastest declines: compared to the $80^{\text {th }}$ percentile SPPB slope (least decline), the relative risk was $0.81(95 \%$ CI $0.63-1.01 ; p=0.09)$ for the $60^{\text {th }}$ percentile of SPPB slope, 0.70 (95\% CI, 0.47-0.99, $p$ $=0.07$ ) for the $40^{\text {th }}$ percentile of SPPB slope and 0.58 (95\% CI, 0.34-0.92, $p=0.02$ ) for the $20^{\text {th }}$ percentile of SPPB slope (Table 3; Fig. 2).

There were no statistically significant associations between risk of microinfarcts, cystic infarcts or atherosclerosis neuropathology outcomes and slope of SPPB decline. However, the pattern of results suggested higher relative risks for microinfarcts and cystic infarcts among the fastest decliners (Table 3; Fig. 3). As shown in the natural cubic spline plots of the relative risks across the range of SPPB slopes (Fig. 3), this pattern of results is consistent with either no association or lower risk of AD pathology (CERAD, Braak, amyloid angiopathy) and higher risk of vascular (microinfarcts and cystic infarcts) neuropathology among decedents with faster rates of SPPB decline.

When we examined the predicted SPPB scores 5 years prior to death in relation to the neuropathology outcomes, we observed higher risks for lower SPPB scores for all neuropathology outcomes except for amyloid angiopathy; the highest relative risks were observed for microinfarcts $(\mathrm{RRs}=2.24$ and 3.08 for the 40th and 20th vs. 80th percentiles of SPPB scores, respectively) and cystic infarcts ( $R R s=2.42$ and 2.72 for the 40th and 20th vs. 80th percentiles of SPPB scores, respectively; Table 4). The relative risks had wide $95 \%$ confidence intervals and were only statistically significant for cystic infarcts. The natural cubic spline plots for these relative risks 
Table 1 Characteristics of ACT autopsy cohort at last study visit by estimated SPPB slope quartiles ${ }^{\mathrm{a}}$

\begin{tabular}{|c|c|c|c|c|}
\hline & $\begin{array}{l}\text { SPPB }>75^{\text {th }} \text { percentile slope } \\
\text { (slower decline) }(N=76)\end{array}$ & $\begin{array}{l}\text { SPPB 50th }-75^{\text {th }} \\
\text { percentile slope }(N=76)\end{array}$ & $\begin{array}{l}\text { SPPB } 25 \text { th }-50^{\text {th }} \\
\text { percentile slope }(N=76)\end{array}$ & $\begin{array}{l}\text { SPPB }<25^{\text {th }} \text { percentile slope } \\
\text { (faster decline) }(N=77)\end{array}$ \\
\hline & N (\%) & N (\%) & N (\%) & N (\%) \\
\hline \multicolumn{5}{|l|}{ Cohort } \\
\hline $\begin{array}{l}\text { Original } \\
\text { cohort }\end{array}$ & $62(81.6)$ & $66(86.8)$ & $64(84.2)$ & $70(90.9)$ \\
\hline $\begin{array}{l}\text { Expansion } \\
\text { cohort }\end{array}$ & $14(18.4)$ & $9(11.8)$ & $12(15.8)$ & $6(7.8)$ \\
\hline $\begin{array}{l}\text { Replacement } \\
\text { cohort }\end{array}$ & $0(0.0)$ & $1(1.3)$ & $0(0.0)$ & $1(1.3)$ \\
\hline \multicolumn{5}{|l|}{ Sex } \\
\hline Male & $44(57.9)$ & $38(50.0)$ & $33(43.4)$ & $25(32.5)$ \\
\hline Female & $32(42.1)$ & $38(50.0)$ & $43(56.6)$ & $52(67.5)$ \\
\hline \multicolumn{5}{|l|}{ Age at baseline } \\
\hline$<70$ years & $0(0.0)$ & $4(5.3)$ & $4(5.3)$ & $3(3.9)$ \\
\hline 70-74 years & $5(6.6)$ & $18(23.7)$ & $12(15.8)$ & $12(15.6)$ \\
\hline $75-79$ years & $21(27.6)$ & $10(13.2)$ & $16(21.1)$ & $28(36.4)$ \\
\hline $80-84$ years & $27(35.5)$ & $21(27.6)$ & $22(28.9)$ & $23(29.9)$ \\
\hline $85+$ years & $23(30.3)$ & $23(30.3)$ & $22(28.9)$ & $11(14.3)$ \\
\hline \multicolumn{5}{|c|}{ BMI at last $A C T$ study visit } \\
\hline $\begin{array}{l}\text { Underweight } \\
(<18.5)\end{array}$ & $3(4.0)$ & $0(0.0)$ & $1(1.4)$ & $1(1.3)$ \\
\hline $\begin{array}{l}\text { Normal weight } \\
(18.5-24.99)\end{array}$ & $34(45.3)$ & $39(54.2)$ & $31(42.5)$ & $23(30.7)$ \\
\hline $\begin{array}{l}\text { Overweight } \\
(25-29.99)\end{array}$ & $33(44.0)$ & $25(34.7)$ & $25(34.2)$ & $34(45.3)$ \\
\hline Obese (30+) & $5(6.7)$ & $8(11.1)$ & $16(21.9)$ & $17(22.7)$ \\
\hline \multicolumn{5}{|l|}{ Dementia } \\
\hline No dementia & $44(57.9)$ & 39 (51.3) & $43(56.6)$ & $37(48.1)$ \\
\hline Dementia & $32(42.1)$ & $37(48.7)$ & $33(43.4)$ & $40(51.9)$ \\
\hline \multicolumn{5}{|c|}{ Possible or probable AD } \\
\hline No AD & $47(61.8)$ & $51(67.1)$ & $51(67.1)$ & $46(59.7)$ \\
\hline$A D$ & $29(38.2)$ & $25(32.9)$ & $25(32.9)$ & $31(40.3)$ \\
\hline \multicolumn{5}{|l|}{ Education } \\
\hline$<12$ years & $3(3.9)$ & $15(19.7)$ & $8(10.5)$ & $7(9.1)$ \\
\hline $12-15$ years & $37(48.7)$ & $33(43.4)$ & $40(52.6)$ & $47(61.0)$ \\
\hline $16+$ years & $36(47.4)$ & $28(36.8)$ & $28(36.8)$ & $23(29.9)$ \\
\hline \multicolumn{5}{|c|}{ Smoking at last visit } \\
\hline Never & $30(39.5)$ & $32(42.1)$ & $31(40.8)$ & $27(35.1)$ \\
\hline Former & $42(55.3)$ & $40(52.6)$ & $40(52.6)$ & $44(57.1)$ \\
\hline Current & $4(5.3)$ & $4(5.3)$ & $5(6.6)$ & $6(7.8)$ \\
\hline \multicolumn{5}{|c|}{ Regular exercise at last visit } \\
\hline No & $21(28.0)$ & $21(27.6)$ & $36(48.0)$ & $36(47.4)$ \\
\hline Yes & $54(72.0)$ & $55(72.4)$ & $39(52.0)$ & $40(52.6)$ \\
\hline \multicolumn{5}{|c|}{ SPPB: gait speed ${ }^{\mathrm{a}}$ component (0-4) at baseline } \\
\hline 1 & $1(1.3)$ & $4(5.3)$ & $9(11.8)$ & $15(19.5)$ \\
\hline 2 & $1(1.3)$ & $10(13.2)$ & $8(10.5)$ & $14(18.2)$ \\
\hline 3 & $28(36.8)$ & $32(42.1)$ & $34(44.7)$ & $34(44.2)$ \\
\hline
\end{tabular}


Table 1 Characteristics of ACT autopsy cohort at last study visit by estimated SPPB slope quartiles ${ }^{\mathrm{a}}$ (Continued)

\begin{tabular}{|c|c|c|c|c|}
\hline & $\begin{array}{l}\text { SPPB }>75^{\text {th }} \text { percentile slope } \\
\text { (slower decline) }(N=76)\end{array}$ & $\begin{array}{l}\text { SPPB 50th }-75^{\text {th }} \\
\text { percentile slope }(N=76)\end{array}$ & $\begin{array}{l}\text { SPPB 25th }-50^{\text {th }} \\
\text { percentile slope }(N=76)\end{array}$ & $\begin{array}{l}\text { SPPB }<25^{\text {th }} \text { percentile slope } \\
\text { (faster decline) }(N=77)\end{array}$ \\
\hline & N (\%) & N (\%) & N (\%) & N (\%) \\
\hline 4 & $46(60.5)$ & $30(39.5)$ & 25 (32.9) & 14 (18.2) \\
\hline Grip s & & & & \\
\hline 0 & $2(2.6)$ & $0(0.0)$ & $0(0.0)$ & $0(0.0)$ \\
\hline 1 & $5(6.6)$ & $10(13.2)$ & 14 (18.4) & $6(7.8)$ \\
\hline 2 & 15 (19.7) & $17(22.4)$ & $14(18.4)$ & $28(36.4)$ \\
\hline 3 & 39 (51.3) & $31(40.8)$ & 30 (39.5) & 33 (42.9) \\
\hline 4 & 15 (19.7) & $18(23.7)$ & $18(23.7)$ & $10(13.0)$ \\
\hline
\end{tabular}

${ }^{a}$ SPPB slope percentile values: 75 th percentile $=-0.148,50$ th percentile $=-0.196,25$ th percentile $=-0.256$

${ }^{\mathrm{b}}$ Gait speed and grip strength are rated on a 0-4 scale with 0 indicating unable to perform test, and higher scores indicating greater function (faster gait speed and stronger grip strength). Scales are defined based on sex-specific cutpoints: grip strength (male: $<25 \mathrm{~kg}, 25$ to $<30,30$ to $<40$, and $\geq 40$; female: $<15 \mathrm{~kg}$,

15 to $<20,20$ to $<25$, and $\geq 25$ ); gait speed based on time to walk 10 -ft (men: $\geq 5 \mathrm{~s}, 4.5 \mathrm{~s}, 3.5$ to $4 \mathrm{~s}$, and $\leq 3 \mathrm{~s}$; women: $\geq 5.5 \mathrm{~s}, 4.5$ to $5 \mathrm{~s}, 3.5$ to $4 \mathrm{~s}$, and $\leq 3 \mathrm{~s}$ )

Table 2 Unadjusted proportions for binary neuropathology outcomes according to quartiles ${ }^{\mathrm{a}}$ of SPPB slope

\begin{tabular}{|c|c|c|c|c|}
\hline & $\begin{array}{l}\text { SPPB }>75^{\text {th }} \text { percentile slope } \\
\text { (slower decline) }(N=76)\end{array}$ & $\begin{array}{l}\text { SPPB 50th }-75^{\text {th }} \\
\text { percentile slope }(N=76)\end{array}$ & $\begin{array}{l}\text { SPPB 25th }-50^{\text {th }} \\
\text { percentile slope }(N=76)\end{array}$ & $\begin{array}{l}\text { SPPB }<25^{\text {th }} \text { percentile slope } \\
\text { (faster decline) }(N=77)\end{array}$ \\
\hline & $N(\%)$ & $N(\%)$ & $N(\%)$ & $N(\%)$ \\
\hline \multicolumn{5}{|l|}{ CERAD (plaques) } \\
\hline $\begin{array}{l}\text { Intermediate/ } \\
\text { frequent }\end{array}$ & $40(52.6)$ & $31(40.8)$ & $35(46.1)$ & $41(53.2)$ \\
\hline None/sparse & $36(47.4)$ & $45(59.2)$ & $41(53.9)$ & $36(46.8)$ \\
\hline \multicolumn{5}{|l|}{ Braak (tangles) } \\
\hline $\mathrm{V}-\mathrm{VI}$ & $29(38.2)$ & $17(22.4)$ & $25(32.9)$ & $25(32.5)$ \\
\hline 0-IV & $47(61.8)$ & $59(77.6)$ & $51(67.1)$ & $52(67.5)$ \\
\hline \multicolumn{5}{|l|}{ Amyloid angiopathy } \\
\hline $\begin{array}{l}\text { Mild, moderate, } \\
\text { or severe }\end{array}$ & $25(32.9)$ & $23(30.7)$ & $18(24.0)$ & $22(28.6)$ \\
\hline None & $51(67.1)$ & $52(69.3)$ & $57(76.0)$ & $55(71.4)$ \\
\hline \multicolumn{5}{|l|}{ Microinfarcts } \\
\hline $\begin{array}{l}>2 \text { cerebral } \\
\text { or deep }\end{array}$ & $8(10.5)$ & $5(6.6)$ & $9(11.8)$ & $21(27.3)$ \\
\hline $\begin{array}{l}<=2 \text { cerebral } \\
\text { or deep }\end{array}$ & $68(89.5)$ & $71(93.4)$ & $67(88.2)$ & $56(72.7)$ \\
\hline \multicolumn{5}{|l|}{ Cystic infarcts } \\
\hline 1 or more & $14(18.9)$ & $22(30.1)$ & $25(34.2)$ & $24(31.2)$ \\
\hline None & $60(81.1)$ & $51(69.9)$ & $48(65.8)$ & $53(68.8)$ \\
\hline \multicolumn{5}{|l|}{ Atherosclerosis } \\
\hline $2-3$ & $45(62.5)$ & $44(58.7)$ & $35(50.0)$ & $48(63.2)$ \\
\hline $0-1$ & $27(37.5)$ & $31(41.3)$ & $35(50.0)$ & $28(36.8)$ \\
\hline \multicolumn{5}{|c|}{ Cortical Lewy bodies } \\
\hline 1 & $3(3.9)$ & $6(8.0)$ & $5(6.6)$ & $3(3.9)$ \\
\hline 0 & $73(96.1)$ & $69(92.0)$ & $71(93.4)$ & 74 (96.1) \\
\hline
\end{tabular}

${ }^{\mathrm{a}}$ SPPB slope percentile values: $75^{\text {th }}$ percentile $=-0.148,50^{\text {th }}$ percentile $=-0.196,25$ th percentile $=-0.256$ 
Table 3 Relative risks for neuropathology outcomes by rate of change in SPPB

\begin{tabular}{|c|c|c|c|c|}
\hline & \multirow[t]{2}{*}{ Rate of change of SPPB } & \multicolumn{3}{|c|}{ Risk of neuropath outcomes } \\
\hline & & $\overline{\mathrm{RR}}$ & $95 \% \mathrm{Cl}$ & $P$ \\
\hline \multicolumn{5}{|c|}{ CERAD (plaques) (intermediate/frequent) } \\
\hline $80^{\text {th }}$ percentile (slower decline) & -0.124 & Ref & - & - \\
\hline 60 & -0.163 & 0.88 & $(0.74,1.05)$ & 0.14 \\
\hline 40 & -0.197 & 0.82 & $(0.62,1.07)$ & 0.158 \\
\hline $20^{\text {th }}$ percentile (faster decline) & -0.251 & 0.80 & $(0.57,1.14)$ & 0.212 \\
\hline \multicolumn{5}{|l|}{ Braak (tangles) (V-VI) } \\
\hline $80^{\text {th }}$ percentile (slower decline) & -0.124 & Ref & - & - \\
\hline 60 & -0.163 & 0.81 & $(0.65,1.07)$ & 0.12 \\
\hline 40 & -0.197 & 0.72 & $(0.51,1.09)$ & 0.11 \\
\hline $20^{\text {th }}$ percentile (faster decline) & -0.251 & 0.66 & $(0.41,1.02)$ & 0.08 \\
\hline \multicolumn{5}{|c|}{ Amyloid angiopathy (mild, moderate, or severe) } \\
\hline $80^{\text {th }}$ percentile (slower decline) & -0.124 & Ref & - & - \\
\hline 60 & -0.163 & 0.81 & $(0.63,1.01)$ & 0.09 \\
\hline 40 & -0.197 & 0.70 & $(0.47,0.99)$ & 0.07 \\
\hline $20^{\text {th }}$ percentile (faster decline) & -0.251 & 0.58 & $(0.34,0.92)$ & 0.02 \\
\hline \multicolumn{5}{|l|}{ Microinfarcts (>2 cerebral or deep) } \\
\hline $80^{\text {th }}$ percentile (slower decline) & -0.124 & Ref & - & - \\
\hline 60 & -0.163 & 1.06 & $(0.69,1.61)$ & 0.80 \\
\hline 40 & -0.197 & 1.15 & $(0.57,2.22)$ & 0.72 \\
\hline $20^{\text {th }}$ percentile (faster decline) & -0.251 & 1.45 & $(0.55,3.61)$ & 0.41 \\
\hline \multicolumn{5}{|l|}{ Cystic infarcts (1 or more) } \\
\hline $80^{\text {th }}$ percentile (slower decline) & -0.124 & Ref & - & - \\
\hline 60 & -0.163 & 1.35 & $(1.00,1.82)$ & 0.04 \\
\hline 40 & -0.197 & 1.58 & $(0.97,2.50)$ & 0.06 \\
\hline $20^{\text {th }}$ percentile (faster decline) & -0.251 & 1.64 & $(0.84,2.92)$ & 0.11 \\
\hline \multicolumn{5}{|l|}{ Atherosclerosis (2-3) } \\
\hline $80^{\text {th }}$ percentile (slower decline) & -0.124 & Ref & - & - \\
\hline 60 & -0.163 & 0.96 & $(0.85,1.11)$ & 0.51 \\
\hline 40 & -0.197 & 0.94 & $(0.79,1.21)$ & 0.59 \\
\hline $20^{\text {th }}$ percentile (faster decline) & -0.251 & 0.98 & $(0.79,1.35)$ & 0.88 \\
\hline
\end{tabular}

Relative risks are computed for 20th, 40th, and 60th percentiles of slope relative to 80th percentile of slope. Adjusted for sex, age, BMl, and education

illustrate the increased risk of neuropathology outcomes associated with low predicted SPPB scores 5 years prior to death (Fig. 4).

\section{Discussion}

Based on up to 16 years of follow-up and 2-9 measurements of SPPB among 3174 men and women aged 65 and older, we observed considerable variability in the trajectories of physical function in the ACT cohort. Some older adults maintained function almost entirely, while others lost function at a very rapid rate. Among decedents for whom we had autopsy neuropathology data, there was no evidence of increased risk in AD pathology as assessed by CERAD level and Braak stage associated with more rapid decline in SPPB scores. In fact, we found suggestions that the risk of plaques, tangles and amyloid angiopathy were in the opposite direction, significantly so for amyloid angiopathy, suggesting a somewhat lower rate 

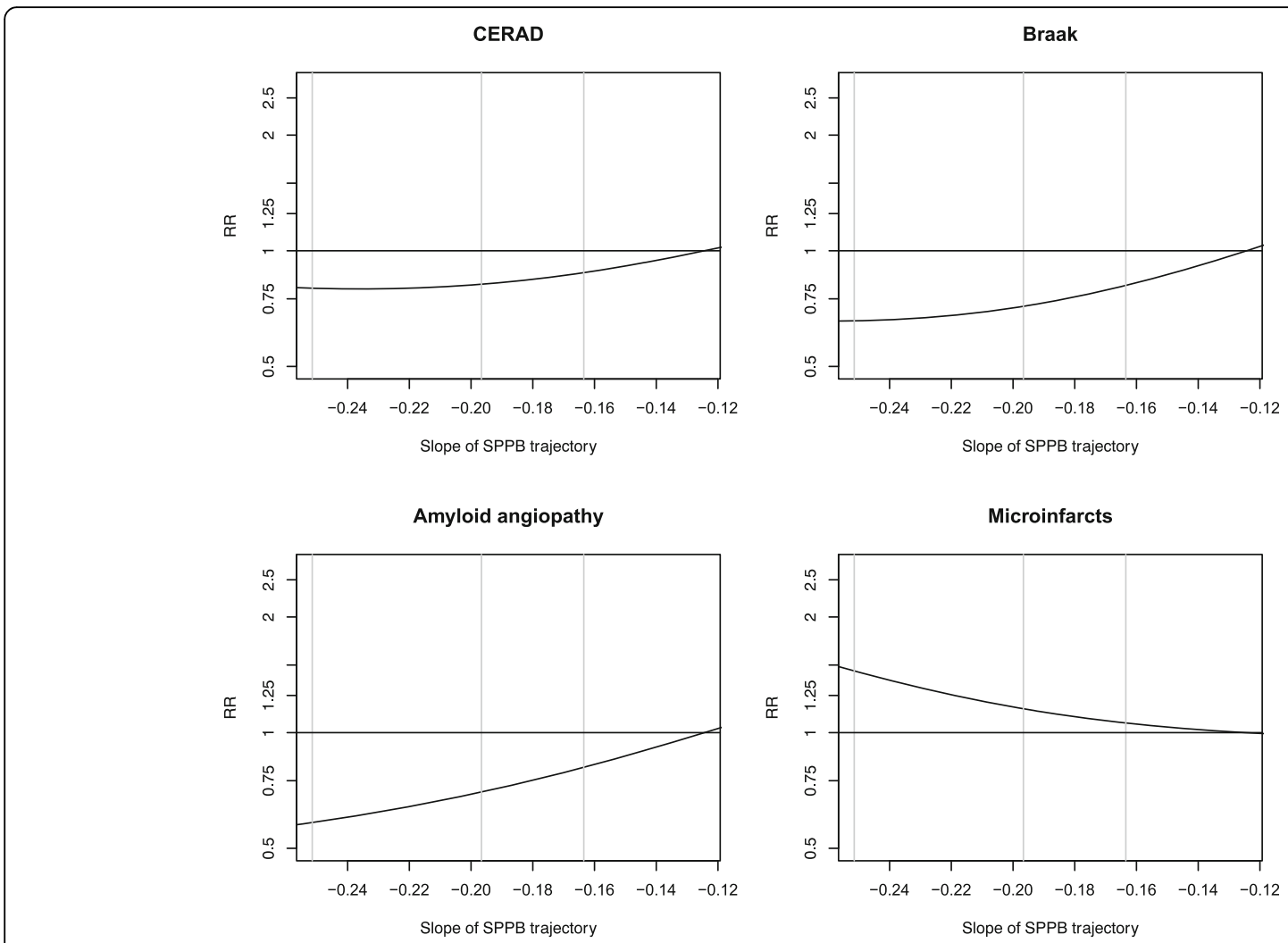

Cystic infarcts
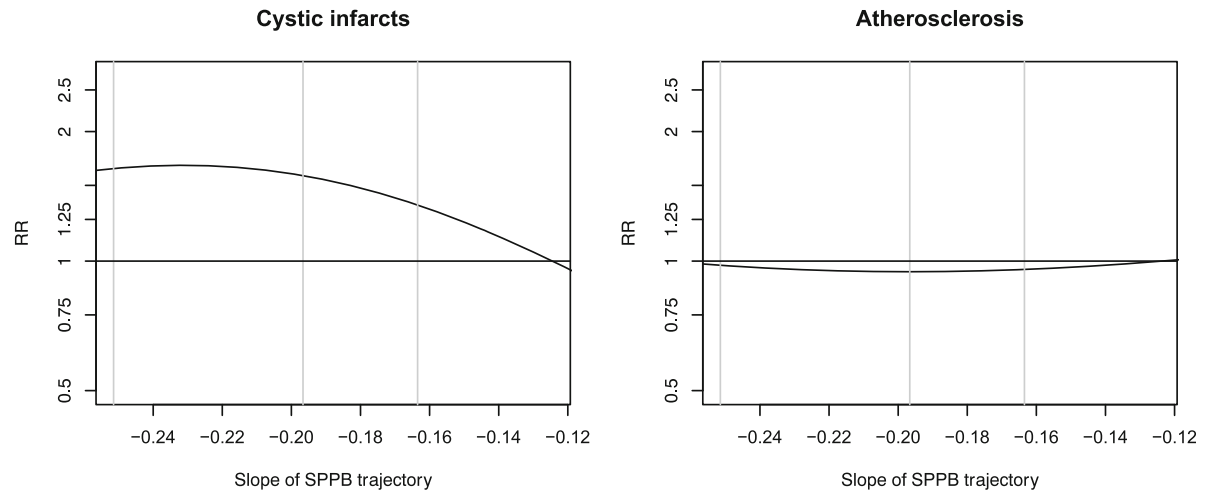

Fig. 3 Relative risks ${ }^{a}$ relating slope of SPPB with neuropathology outcomes based on natural cubic splines. ${ }^{a}$ Model includes slope estimated via weighted GEE adjusted for sex, age, BMI, and education computed relative to the $80^{\text {th }}$ percentile of SPPB slope. Vertical lines indicate $20^{\text {th }}, 40^{\text {th }}$, and $60^{\text {th }}$ percentiles of SPPB slope

of these pathologies in people with relatively rapidly declining SPPB scores. In contrast, relative risks for the vascular neuropathologies of microinfarcts and cystic infarcts were higher among people with relatively rapidly declining SPPB scores, though not significantly elevated for any type of lesion. Relative risks for all of the pathological findings were in the direction of increased risk when we examined estimated SPPB scores 5 years prior to death. The relative risks were highest for microinfarcts and cystic infarcts suggesting a 2-3 fold increased risk of these neuropathologies among decedents with the lowest predicted SPPB score. However, statistically significant associations were observed only for cystic infarcts.

Evidence has accumulated over the last decade that physical and cognitive function are linked. Numerous 
Table 4 Relative risks ${ }^{\mathrm{a}}$ for neuropathology outcomes for percentiles of estimated SPPB 5 years before death

\begin{tabular}{|c|c|c|c|c|}
\hline & SPPB 5 years before death & Risk & tcomes & \\
\hline & & $\overline{R^{b}}$ & $95 \% \mathrm{Cl}$ & $P$ \\
\hline CERAD (plaques) (intermediate/f & & & & \\
\hline $80^{\text {th }}$ percentile (higher SPPB) & 9.98 & Ref & - & - \\
\hline 60 & 9.02 & 1.16 & $(0.94,1.51)$ & 0.24 \\
\hline 40 & 7.86 & 1.35 & $(0.94,2.17)$ & 0.15 \\
\hline $20^{\text {th }}$ percentile (lower SPPB) & 6.46 & 1.55 & $(1.02,2.73)$ & 0.06 \\
\hline Braak (tangles) (V-VI) & & & & \\
\hline $80^{\text {th }}$ percentile (higher SPPB) & 9.98 & Ref & - & - \\
\hline 60 & 9.02 & 1.16 & $(0.87,1.55)$ & 0.31 \\
\hline 40 & 7.86 & 1.33 & $(0.80,2.24)$ & 0.29 \\
\hline $20^{\text {th }}$ percentile (lower SPPB) & 6.46 & 1.47 & $(0.81,2.80)$ & 0.24 \\
\hline Amyloid angiopathy (mild, mod & & & & \\
\hline $80^{\text {th }}$ percentile (higher SPPB) & 9.98 & Ref & - & - \\
\hline 60 & 9.02 & 0.93 & $(0.70,1.24)$ & 0.63 \\
\hline 40 & 7.86 & 0.89 & $(0.52,1.48)$ & 0.66 \\
\hline 20th percentile (lower SPPB) & 6.46 & 0.93 & $(0.51,1.67)$ & 0.78 \\
\hline Microinfarcts ( $>2$ cerebral or dee & & & & \\
\hline $80^{\text {th }}$ percentile (higher SPPB) & 9.98 & Ref & - & - \\
\hline 60 & 9.02 & 1.50 & $(0.88,2.57)$ & 0.13 \\
\hline 40 & 7.86 & 2.24 & $(0.84,6.01)$ & 0.10 \\
\hline $20^{\text {th }}$ percentile (lower SPPB) & 6.46 & 3.08 & $(0.93,10.07)$ & 0.07 \\
\hline Cystic infarcts (1 or more) & & & & \\
\hline $80^{\text {th }}$ percentile (higher SPPB) & 9.98 & Ref & - & - \\
\hline 60 & 9.02 & 1.64 & $(1.17,2.32)$ & 0.002 \\
\hline 40 & 7.86 & 2.42 & $(1.37,4.51)$ & 0.002 \\
\hline $20^{\text {th }}$ percentile (lower SPPB) & 6.46 & 2.72 & $(1.45,5.57)$ & 0.005 \\
\hline Atherosclerosis (2-3) & & & & \\
\hline $80^{\text {th }}$ percentile (higher SPPB) & 9.98 & Ref & - & - \\
\hline 60 & 9.02 & 1.17 & $(0.95,1.39)$ & 0.11 \\
\hline 40 & 7.86 & 1.33 & $(0.93,1.80)$ & 0.10 \\
\hline $20^{\text {th }}$ percentile (lower SPPB) & 6.46 & 1.43 & $(0.96,1.99)$ & 0.08 \\
\hline
\end{tabular}

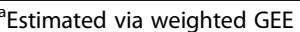

${ }^{\mathrm{b}}$ Relative risks are computed for $20^{\text {th }}, 40^{\text {th }}$, and $60^{\text {th }}$ percentiles relative to 80th percentiles from modified Poisson regression models adjusted for sex, age, $\mathrm{BMI}$, and education

associations have been observed in prospective studies that examined each domain of functional status in relation to the future trajectory of the other [27]. Epidemiologic studies have also established associations between frailty and incidence of mild cognitive impairment [28], Alzheimer's Disease [29], and dementia $[9,10,30]$. In our previous study on this topic in the ACT cohort, frailty was associated with higher risk for dementia $(H R=1.2)$, but the association was solely due to an increased risk of non-AD dementia $(\mathrm{HR}=2.6)$, and was not apparent for AD dementia [10]. Similarly, in the Italian Longitudinal Study of Aging, Solfrizzi [9] and colleagues found that frailty was associated with a decreased risk of $\mathrm{AD}(\mathrm{HR}=0.62)$, but an increased risk of vascular and other dementias $(\mathrm{HRs}=2.7)$. These findings align well with this report in which risks of micro- and cystic infarcts were higher among those 

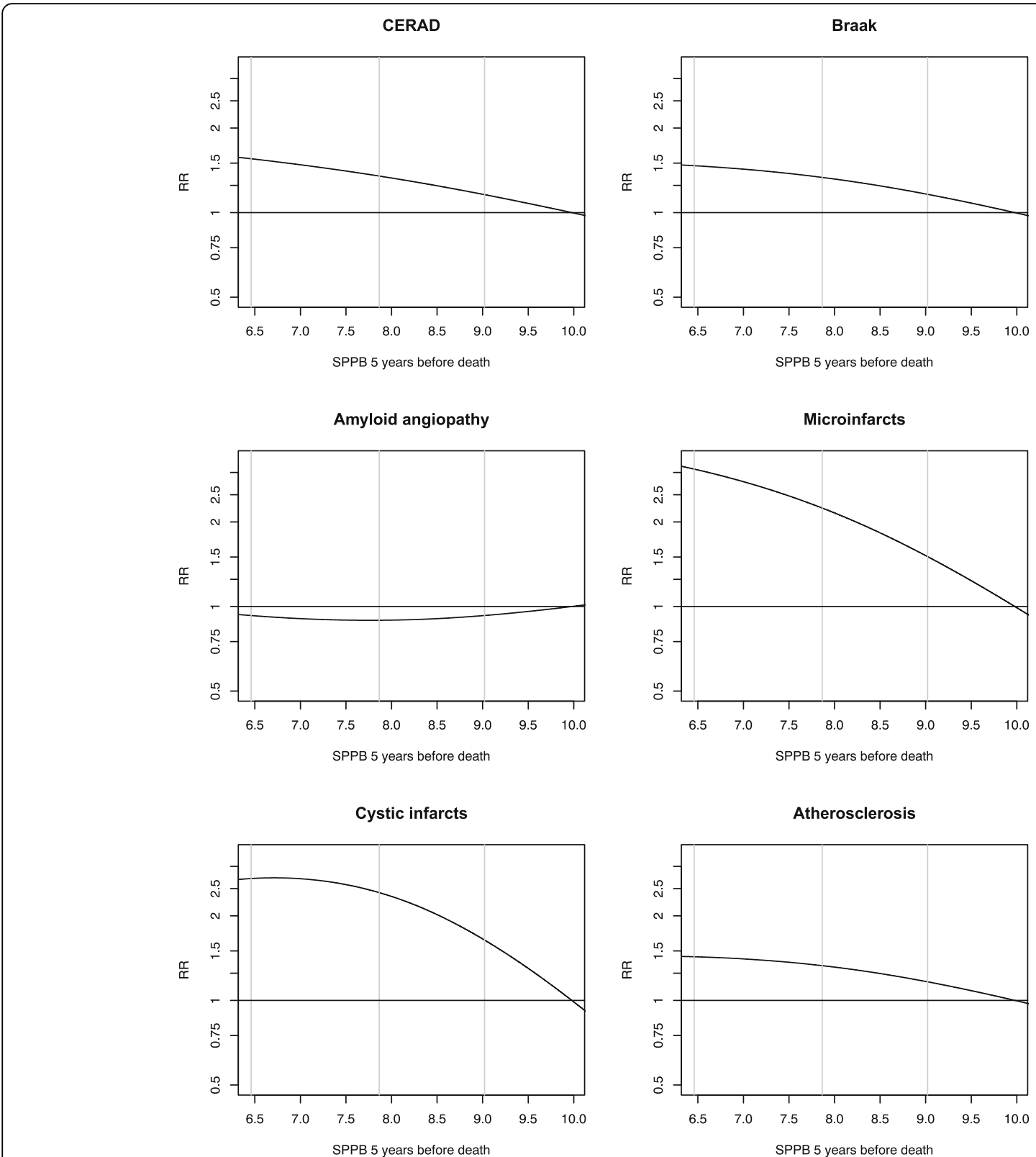

Fig. 4 Relative risks ${ }^{a}$ relating estimated SPPB 5 years before death to neuropathology outcomes. ${ }^{a}$ Model includes SPPB 5 years before death estimated via weighted GEE adjusted for sex, age, BMI, and education computed relative to the $80^{\text {th }}$ percentile of SPPB slope. Vertical lines indicate $20^{\text {th }}, 40^{\text {th }}$, and $60^{\text {th }}$ percentiles of SPPB slope

with the fastest rates of decline in SPPB score, but no increased risks of plaques or tangles were observed.

In the present study, we also observed increased risks of both $\mathrm{AD}$ and vascular neuropathologies with lower SPPB scores estimated 5 years prior to death. Although highest for micro- and cystic infarcts and statistically significant only for cystic infarcts, relative risks were in the direction of increased risk for lower SPPB scores estimated 5 years before death. Among 791 older adults from the Religious Orders Study and the Rush Memory and Aging Project, a faster rate of change in frailty in the 6 years prior to death was associated with many AD and vascular pathology findings, although together the brain lesions explained only $8 \%$ of the variation in frailty progression [7]. When 
considered together with our results from the estimated SPPB five years prior to death, these findings suggest that neuropathological findings of any type are associated with lower levels of physical performance in the years just prior to death. Our findings on slopes suggest that higher rates of functional decline may be especially likely for people with vascular pathology. Such observations may reflect some terminal decline that occurs simultaneously in many functional domains, but is not specific to a particular brain disease. A recent review of frailty and cognitive impairment concluded that the observed reciprocal relationships suggest "that cognition and frailty interact within a cycle of decline associated with ageing" [31].

The common element between the constructs of frailty and SPPB is gait speed as measured by timed gait. In a recent review of 27 studies examining gait speed in relation to structural brain findings on MRI, numerous associations between gait speed and white and gray matter volume have been observed, but the evidence base is quite mixed and inconsistent [5]. For example, in the Cardiovascular Health Study, slower gait speed and faster decline in gait speed were associated with ventricular enlargement and white matter hyperintensities on $\operatorname{MR}[32,33]$, but confirmatory evidence is lacking. Strong crosssectional associations between SPPB and severity of age-related white matter changes have also been observed in the Leukoaraiosis and Disability Study (LADIS) [34]. Studies of global brain networks are being done in an effort to understand the impact of functional changes in the brain in relation to mobility changes in older adults. A recent, small study found striking differences among older adults with low and high SPPB scores in connectivity in the somatomotor cortex [35]. While much remains to be learned about how cognitive aging and subclinical cognitive diseases affect trajectories of physical function in the last decades of life, the emerging evidence suggests a definite role of brain aging and disease in this process.

Although the evidence above supports the biologic plausibility of a role for brain aging and disease in physical function losses with aging, there are many alternative explanations. An association of declining physical function with vascular neuropathological findings could be explained by an impact of brain function on motor ability [4], or the associations could be explained by shared, underlying vascular pathology in the microvasculature and common impacts of risk factors that contribute to microvascular disease such as inflammation and oxidative stress. The different associations between trajectories of SPPB and AD vs. vascular neuropathology point to different etiologies, and future longitudinal studies should examine whether cardiovascular disease and risk factors mediate this association. Our analyses adjust for sex, age, education and BMI, but we did not measure biomarker levels in the ACT cohort.

Strengths of our study include the evaluation of a population-based autopsy cohort with well characterized health status, health behaviors, physical function and cognitive status over time, as well as state-of-the-art methods for ascertaining brain neuropathology. We accounted for selection factors related to inclusion in the autopsy cohort by applying inverse-probability weights to improve generalizability of these results to the entire population-based cohort. We were able to study SPPB trajectories using up to 9 measurements; $75 \%$ of study participants had at least 3 SPPB measurements. Follow-up time in the autopsy cohort is shorter than the entire cohort, because participants are necessarily censored at time of death. In addition, in the ACT cohort, once a participant exhibits decline in global cognition as measured by the CASI score, they are evaluated for dementia using standardized protocols. If dementia is identified, the participant has a single follow-up visit using the same protocol, and if dementia is confirmed, they are followed only by telephone, without further measures of the SPPB, which requires an in-person visit. Thus, the SPPB measurements used in this analysis were all measured before any participants had a clinical diagnosis of dementia. This study was limited by the relatively small sample size of autopsied ACT decedents. We did not have measurements of long-tract white matter disease to include in this analysis and numbers of autopsies with corticol Lewy body indices were too small to produce meaningful results. Future studies should examine an expanded array of brain neuropathologies in relation to physical function prior to death.

\section{Conclusion}

Cystic infarcts and microinfarcts, but not neuropathology findings of Alzheimer's disease, were related to physical performance levels five years before death. The rate of physical performance decline was not associated with either vascular or Alzheimer's disease brain neuropathology. These findings add to accumulating evidence that brain aging and disease contribute to physical function levels in older people in the years preceding death. The findings support identifying modifiable risk factors associated with vascular neuropathological findings and testing whether intervening on these risk factors can preserve physical function and reduce brain neuropathology in older adults. 


\section{Appendix}

Table 5 Characteristics of all ACT participants at last study visit by quartiles of SPPB slope

\begin{tabular}{|c|c|c|c|c|}
\hline & $\begin{array}{l}\text { SPPB }>75 \text { th percentile slope } \\
\text { (slower decline) }(N=872)\end{array}$ & $\begin{array}{l}\text { SPPB 50th - 75th } \\
\text { percentile slope }(N=803)\end{array}$ & $\begin{array}{l}\text { SPPB 25th - 50th } \\
\text { percentile slope }(N=610)\end{array}$ & $\begin{array}{l}\text { SPPB }<25 \text { th percentile slope } \\
\text { (faster decline) }(N=528)\end{array}$ \\
\hline & $N(\%)$ & $N(\%)$ & $N(\%)$ & $N(\%)$ \\
\hline \multicolumn{5}{|l|}{ Cohort } \\
\hline Original cohort & $574(65.8)$ & $463(57.7)$ & $415(68.0)$ & 415 (78.6) \\
\hline Expansion cohort & $202(23.2)$ & $156(19.4)$ & $123(20.2)$ & $88(16.7)$ \\
\hline $\begin{array}{l}\text { Replacement } \\
\text { cohort }\end{array}$ & $96(11.0)$ & $184(22.9)$ & $72(11.8)$ & $25(4.7)$ \\
\hline \multicolumn{5}{|l|}{ Sex } \\
\hline Male & $410(47.0)$ & $371(46.2)$ & $229(37.5)$ & $164(31.1)$ \\
\hline Female & $462(53.0)$ & $432(53.8)$ & $381(62.5)$ & $364(68.9)$ \\
\hline \multicolumn{5}{|l|}{ Age at baseline } \\
\hline$<70$ years & $33(3.8)$ & $120(14.9)$ & $48(7.9)$ & $26(4.9)$ \\
\hline 70-74 years & $143(16.4)$ & $255(31.8)$ & $149(24.4)$ & $123(23.3)$ \\
\hline $75-79$ years & $241(27.6)$ & $189(23.5)$ & $149(24.4)$ & $172(32.6)$ \\
\hline 80-84 years & $246(28.2)$ & $133(16.6)$ & $157(25.7)$ & $146(27.7)$ \\
\hline $85+$ years & $209(24.0)$ & $106(13.2)$ & $107(17.5)$ & $61(11.6)$ \\
\hline \multicolumn{5}{|c|}{ BMI at last ACT study visit } \\
\hline $\begin{array}{l}\text { Underweight } \\
(<18.5)\end{array}$ & $15(1.7)$ & $12(1.5)$ & $6(1.0)$ & $2(0.4)$ \\
\hline $\begin{array}{l}\text { Normal weight } \\
(18.5-24.99)\end{array}$ & $354(41.1)$ & $283(35.6)$ & $182(30.3)$ & $142(27.4)$ \\
\hline $\begin{array}{l}\text { Overweight } \\
(25-29.99)\end{array}$ & $378(43.9)$ & $332(41.8)$ & $241(40.1)$ & $202(39.0)$ \\
\hline Obese $(30+)$ & $114(13.2)$ & $168(21.1)$ & $172(28.6)$ & $172(33.2)$ \\
\hline \multicolumn{5}{|l|}{ Dementia } \\
\hline No dementia & $698(80.0)$ & $638(79.5)$ & $423(69.3)$ & $361(68.4)$ \\
\hline Dementia & $174(20.0)$ & $165(20.5)$ & $187(30.7)$ & 167 (31.6) \\
\hline \multicolumn{5}{|c|}{ Possible or probable AD } \\
\hline No AD & $720(82.6)$ & $672(83.7)$ & $461(75.6)$ & $398(75.4)$ \\
\hline$A D$ & $152(17.4)$ & $131(16.3)$ & $149(24.4)$ & $130(24.6)$ \\
\hline \multicolumn{5}{|l|}{ Education } \\
\hline$<12$ years & $89(10.2)$ & $71(8.8)$ & $69(11.3)$ & $67(12.7)$ \\
\hline $12-15$ years & $395(45.3)$ & $366(45.6)$ & $316(51.8)$ & $315(59.7)$ \\
\hline $16+$ years & $388(44.5)$ & $366(45.6)$ & $225(36.9)$ & $146(27.7)$ \\
\hline \multicolumn{5}{|l|}{ Smoking at last visit } \\
\hline Never & $427(49.5)$ & $378(47.3)$ & $300(49.5)$ & $241(45.9)$ \\
\hline Former & $419(48.6)$ & $390(48.8)$ & $270(44.6)$ & $260(49.5)$ \\
\hline Current & $17(2.0)$ & $31(3.9)$ & $36(5.9)$ & $24(4.6)$ \\
\hline \multicolumn{5}{|c|}{ Regular exercise at last visit } \\
\hline No & $222(25.7)$ & $262(32.8)$ & $234(38.5)$ & $258(49.2)$ \\
\hline Yes & $643(74.3)$ & $537(67.2)$ & $374(61.5)$ & $266(50.8)$ \\
\hline \multicolumn{5}{|c|}{ SPPB: gait speed ${ }^{a}$ component (0-4) at baseline } \\
\hline 1 & $14(1.6)$ & $35(4.4)$ & $42(6.9)$ & $102(19.3)$ \\
\hline 2 & $31(3.6)$ & $60(7.5)$ & $59(9.7)$ & $91(17.2)$ \\
\hline
\end{tabular}


Table 5 Characteristics of all ACT participants at last study visit by quartiles of SPPB slope (Continued)

\begin{tabular}{cllll}
\hline & $\begin{array}{l}\text { SPPB }>75 \text { th percentile slope } \\
(\text { slower decline) }(N=872)\end{array}$ & $\begin{array}{l}\text { SPPB 50th - 75th } \\
\text { percentile slope }(N=803) \\
N(\%)\end{array}$ & $\begin{array}{l}\text { SPPB 25th - 50th } \\
\text { percentile slope }(N=610) \\
N(\%)\end{array}$ & $\begin{array}{l}\text { SPPB <25th percentile slope } \\
(\text { faster decline) }(N=528) \\
N(\%)\end{array}$ \\
\hline 3 & $260(29.8)$ & $267(33.3)$ & $251(41.1)$ & $194(36.7)$ \\
4 & $567(65.0)$ & $441(54.9)$ & $258(42.3)$ & $141(26.7)$ \\
Grip strength ${ }^{a}$ at baseline & & $6(1.0)$ & $3(0.6)$ \\
0 & $9(1.0)$ & $8(1.0)$ & $66(10.8)$ & $67(12.7)$ \\
1 & $40(4.6)$ & $59(7.3)$ & $137(22.5)$ & $145(27.6)$ \\
2 & $145(16.6)$ & $32(18.9)$ & $249(40.8)$ & $109(39.7)$ \\
4 & $382(43.8)$ & $253(31.5)$ & $152(24.9)$ & $102(19.4)$
\end{tabular}

a Quartiles defined based on ACT autopsy subcohort

${ }^{\mathrm{b}}$ Gait speed and grip strength are rated on a 0-4 scale with 0 indicating unable to perform test, and higher scores indicating greater function (faster gait speed and stronger grip strength). Scales are defined based on sex-specific cutpoints: grip strength (men: $<25 \mathrm{~kg}, 25$ to $<30,30$ to $<40$, and $\geq 40 ;$ women: $<15 \mathrm{~kg}$, 15 to $<20,20$ to $<25$, and $\geq 25$ ); gait speed based on time to walk 10 -ft (men: $\geq 5 \mathrm{~s}, 4.5 \mathrm{~s}, 3.5$ to $4 \mathrm{~s}$, and $\leq 3 \mathrm{~s} ;$ women: $\geq 5.5 \mathrm{~s}, 4.5$ to $5 \mathrm{~s}, 3.5$ to $4 \mathrm{~s}$, and $\leq 3 \mathrm{~s}$ )

\section{Abbreviations}

ACT: Adult Changes in Thought; AD: Alzheimer's Disease; BMl: Body Mass Index; CERAD: Consortium to Establish a Registry for Alzheimer's Disease; GEE: Generalized Estimating Eqs:; GH: Group Health; IPW: Inverse Probability Weights; RR: Relative Risk; SPPB: Short Physical Performance Battery

\section{Acknowledgements}

We thank the ACT investigators, clinicians and study staff at KPWHRI and UW, and especially the ACT study participants who have made this research possible.

\section{Funding}

Data collection and analyses were supported by National Institutes of Health Grant U01 AG006781 (E Larson and P Crane, MPIs).

\section{Availability of data and materials}

The datasets used and/or analyzed during the current study are available from the ACT Repository on reasonable request: KPWA.actproposals@kp.org

\section{Authors' contributions}

AZL led the writing group in designing and implementing the analytic plan, interpreting the data, and was responsible for writing the manuscript. RAH and MLA were responsible for data management in the study and statistical analyses of the data for this report. They also drafted the statistical sections of the manuscript and provided revisions to drafts of the manuscripts. SLG, $\mathrm{PKC}, \mathrm{OZ}$ and EBL contributed to designing the analytic plan and providing critical revisions to drafts of the manuscript. JS was responsible for the neuropathologic examinations of the brain in autopsied participants and he drafted the section in the manuscript describing the methods for these examinations and how the variables were defined. JS also provided critical revisions to drafts of the manuscript. PKC and EBL were responsible for obtaining grant funding for the ACT program. All authors read and approved of the final manuscript.

\section{Authors' information}

Not applicable

\section{Ethics approval and consent to participate}

The study procedures were approved by the institutional review boards of Kaiser Permanente Washington (formerly Group Health Cooperative) and the University of Washington, and participants provided written informed consent.

\section{Consent for publication}

Not applicable

\section{Competing interests}

The authors declare that they have no competing interests.

\section{Publisher's Note}

Springer Nature remains neutral with regard to jurisdictional claims in published maps and institutional affiliations.

\section{Author details}

'Division of Epidemiology, Department of Family Medicine and Public Health, University of California San Diego, 9500 Gilman Drive, La Jolla, CA 92093, USA. ${ }^{2}$ Kaiser Permanente Washington Health Research Institute, 1730 Minor Avenue, Suite 1600, Seattle, WA 98101, USA. ${ }^{3}$ Department of Biostatistics, Epidemiology, and Informatics, University of Pennsylvania, 423 Guardian Drive, Philadelphia, PA 19104, USA. ${ }^{4}$ Schools of Medicine and Pharmacy, University of Washington, 1959 NE Pacific Street, Seattle, WA 98195, USA. ${ }^{5}$ Department of Pathology, University of Utah, 15 North Medical Drive East, Suite 1100, Salt Lake City, UT 84112, USA. ${ }^{6}$ School of Nursing, University of Washington, 1959 NE Pacific Avenue, Seattle, WA 98195, USA.

Received: 8 May 2017 Accepted: 8 October 2017

Published online: 02 November 2017

\section{References}

1. Colby SL, Ortman JM. Projections of the size and composition of the U.S. population: 2014 to 2060, current population reports. Washington, D.C. Census Bureau; 2014. P25-1143. [Google Scholar].

2. Phelan EA, Anderson LA, LaCroix AZ, Larson EB. Older adults' views of "successful aging"-how do they compare with researchers' definitions? J Am Geriatr Soc. 2004;52(2):211-6. doi:https://doi.org/10.1111/j.1532-5415. 2004.52056.x. [PubMed].

3. Buchman AS, Yu L, Wilson RS, Boyle PA, Schneider JA, Bennett DA. Brain pathology contributes to simultaneous change in physical frailty and cognition in old age. J Gerontol A Biol Sci Med Sci. 2014;69(12):1536-44. PubMed Central PMCID: PMC4296120. doi:https://doi.org/10.1093/gerona/ glu117. [PubMed] [Google Scholar].

4. Seidler RD, Bernard JA, Burutolu TB, Fling BW, Gordon MT, Gwin JT, et al. Motor control and aging: links to age-related brain structural, functional, and biochemical effects. Neurosci Biobehav Rev. 2010;34(5):721-33. https:// doi.org/10.1016/j.neubiorev.2009.10.005. [PubMed] [Google Scholar].

5. Kilgour AH, Todd OM, Starr JM. A systematic review of the evidence that brain structure is related to muscle structure and their relationship to brain and muscle function in humans over the lifecourse. BMC Geriatr. 2014;14:85. doi:https://doi.org/10.1186/1471-2318-14-85. [PubMed] [Google Scholar].

6. Buchman AS, Schneider JA, Leurgans S, Bennett DA. Physical frailty in older persons is associated with Alzheimer disease pathology. Neurology. 2008; 71(7):499-504. doi:https://doi.org/10.1212/01.wnl.0000324864.81179.6a. [PubMed] [Google Scholar].

7. Buchman AS, Yu L, Wilson RS, Schneider JA, Bennett DA. Association of brain pathology with the progression of frailty in older adults. Neurology. 2013;80(22):2055-61. doi:https://doi.org/10.1212/WNL.0b013e318294b462. [PubMed] [Google Scholar]. 
8. Avila-Funes JA, Carcaillon L, Helmer C, Carrière I, Ritchie K, Rouaud O, et al. Is frailty a prodromal stage of vascular dementia? Results from the ThreeCity study. J Am Geriatr Soc. 2012;60(9):1708-12. doi:https://doi.org/10.1111/ j.1532-5415.2012.04142.x. [PubMed] [Google Scholar].

9. Solfrizzi V, Scafato E, Frisardi V, Seripa D, Logroscino G, Maggi S, et al. Frailty syndrome and the risk of vascular dementia: the Italian longitudinal study on aging. Alzheimers Dement. 2013;9(2):113-22. doi:https://doi.org/10.1016/ j.jalz.2011.09.223. [PubMed] [Google Scholar].

10. Gray SL, Anderson ML, Hubbard RA, LaCroix A, Crane PK, McCormick W, et al. Frailty and incident dementia. J Gerontol A Biol Sci Med Sci. 2013;68(9): 1083-90. PubMed Central PMCID: PMC3738027. doi:https://doi.org/10.1093/ gerona/glt013. [PubMed] [Google Scholar].

11. Wang L, Larson EB, Bowen JD, van Belle G. Performance-based physical function and future dementia in older people. Arch Intern Med. 2006; 166(10):1115-20. doi:https://doi.org/10.1001/archinte.166.10.115. [PubMed] [Google Scholar].

12. Guralnik JM, Simonsick EM, Ferrucci L, Glynn RJ, Berkman LF, Blazer DG, et al. A short physical performance battery assessing lower extremity function: association with self-reported disability and prediction of mortality and nursing home admission. J Gerontol. 1994;49(2):M85-M94. doi:https://doi. org/10.1093/geronj/49.2.M85. [PubMed] [Google Scholar].

13. Guralnik JM, Ferrucci L, Simonsick EM, Salive ME, Wallace RB. Lowerextremity function in persons over the age of 70 years as a predictor of subsequent disability. N Engl J Med. 1995;332(9):556-61. doi:https://doi.org/ 10.1056/NEJM199503023320902. [PubMed] [Google Scholar].

14. Sonnen JA, Larson EB, Crane PK, Haneuse S, Li G, Schellenberg GD, et al. Pathological correlates of dementia in a longitudinal, population-based sample of aging. Ann Neurol. 2007;62(4):406-13. doi:https://doi.org/10.1002/ ana.21208. [PubMed] [Google Scholar].

15. The National Institute on Aging and Reagan Institute Working Group on Diagnostic Criteria for the Neuropathological Assessment of Alzheimer's Disease (US). Consensus recommendations for the postmortem diagnosis of Alzheimer's disease. Neurobiol Aging. 1997;18(4 suppl):S1-S2. doi:https://doi. org/10.1016/S0197-4580(97)00057-2. [PubMed] [Google Scholar].

16. Mirra SS, Heyman A, McKeel D, Sumi SM, Crain BJ, Brownlee, LM, et al. The consortium to establish a registry for Alzheimer's disease (CERAD). Part II. Standardization of the neuropathologic assessment of Alzheimer's disease. Neurology. 1991;41(4):479-86. doi:https://dx.doi.org/10.1212/WNL.41.4.479. [PubMed] [Google Scholar].

17. Mirra SS. The CERAD neuropathology protocol and consensus recommendations for the postmortem diagnosis of Alzheimer's disease: a commentary. Neurobiol Aging. 1997;18(4 suppl):S91-S94. https://doi.org/10. 1016/S0197-4580(97)00058-4. [PubMed] [Google Scholar].

18. Braak H, Braak E. Neuropathological stageing of Alzheimer-related changes. Acta Neuropathol. 1991;82(4):239-59. doi:https://doi.org/10.1007/ BF00308809. [PubMed] [Google Scholar].

19. Braak E, Griffing K, Arai K, Bohl J, Bratzke H, Braak H. Neuropathology of Alzheimer's disease: what is new since a. Alzheimer? Eur Arch Psychiatry Clin Neurosci. 1999;249(Suppl 3):S14. doi:https://doi.org/10.1007/PL00014168. [PubMed] [Google Scholar].

20. Greenberg SM, Vonsattel JP. Diagnosis of cerebral amyloid angiopathy. Sensitivity and specificity of cortical biopsy. Stroke. 1997;28(7):1418-22. doi: https://doi.org/10.1161/01.STR.28.7.1418. [PubMed].

21. Hyman BT, Phelps CH, Beach TG, Bigio EH, Cairns NJ, Carrillo MC, et al. National Institute on Aging-Alzheimer's Association guidelines for the neuropathologic assessment of Alzheimer's disease. Alzheimers Dement. 2012;8(1):1-13. doi: https://doi.org/10.1016/j.jalz.2011.10.007. [PubMed] [Google Scholar].

22. Montine TJ, Phelps CH, Beach TG, Bigio EH, Cairns NJ, Dickson DW, et al. National Institute on Aging-Alzheimer's Association guidelines for the neuropathologic assessment of Alzheimer's disease: a practical approach. Acta Neuropathol. 2012;123(1):1-11. https://doi.org/10.1007/s00401-0110910-3. [PubMed] [Google Scholar].

23. Crane PK, Gibbons LE, Dams-O'connor K, Trittschuh E, Leverenz JB, Keene CD, Sonnen J, Montine TJ, Bennett DA, Leurgans S, Schneider JA, Larson EB. Association of Traumatic Brain Injury with Late-Life Neurodegenerative Conditions and Neuropathologic Findings. JAMA Neurol. 2016;73(9):1062-9. https://doi.org/10.1001/jamaneurol.2016.1948. [PubMed] [Google Scholar].

24. Kukull WA, Higdon R, Bowen JD, McCormick WC, Teri L, Schellenberg GD, et al. Dementia and Alzheimer disease incidence: a prospective cohort study.
Arch Neurol. 2002;59(11):1737-46.https://doi.org/10.1001/archneur.59.11. 1737. [PubMed] [Google Scholar].

25. Zou, G. A modified poisson regression approach to prospective studies with binary data. Am J Epidemiol. 2004;159(7):702-6. https://doi.org/10.1093/aje/ kwh090. [PubMed] [Google Scholar].

26. Efron B. Better bootstrap confidence intervals. J Am Stat Assoc. 1987;82(397): 171-85. [Google Scholar].

27. Montero-Odasso M, Verghese J, Beauchet O, Hausdorff JM. Gait and cognition: a complementary approach to understanding brain function and the risk of falling. J Am Geriatr Soc. 2012;60(11):2127-36. https://doi.org/10. 1111/j.1532-5415.2012.04209.x. [PubMed] [Google Scholar].

28. Boyle PA, Buchman AS, Wilson RS, Leurgans SE, Bennett DA. Physical frailty is associated with incident mild cognitive impairment in community-based older persons. J Am Geriatr Soc. 2010;58(2):248-55. https://doi.org/10.1111/j. 1532-5415.2009.02671.x. [PubMed] [Google Scholar].

29. Buchman AS, Boyle PA, Wilson RS, Tang Y, Bennett DA. Frailty is associated with incident Alzheimer's disease and cognitive decline in the elderly. Psychosom Med. 2007;69(5):483-9. https://doi.org/10.1097/psy. Ob013e318068de1d. [PubMed] [Google Scholar].

30. Song X, Mitnitski A, Rockwood K. Nontraditional risk factors combine to predict Alzheimer disease and dementia. Neurology. 2011;77(3):227-34. doi: http://dx.doi.org/10.1212/WNL.0b013e318225c6bc. [PubMed] [Google Scholar].

31. Robertson DA, Savva GM, Kenny RA. Frailty and cognitive impairment-a review of the evidence and causal mechanisms. Ageing Res Rev. 2013;12(4): 840-51. doi:https://doi.org/10.1016/j.arr.2013.06.004. [PubMed] [Google Scholar].

32. Rosano C, Brach J, Longstreth WT Jr, Newman AB. Quantitative measures of gait characteristics indicate prevalence of underlying subclinical structural brain abnormalities in high-functioning older adults. Neuroepidemiology. 2006;26(1):52-60. https://doi.org/10.1159/000089240. [PubMed] [Google Scholar]. [PubMed] [Google Scholar].

33. Rosano C, Kuller LH, Chung H, Arnold AM, Longstreth WT Jr, Newman AB. Subclinical brain magnetic resonance imaging abnormalities predict physical functional decline in high-functioning older adults. J Am Geriatr Soc. 2005;53(4):649-54. doi:https://doi.org/10.1111/j.1532-5415.2005.53214.x. [PubMed] [Google Scholar].

34. Baezner $H$, Blahak C, Poggesi A, Pantoni L, Inzitari D, Chabriat $H$, Erkinjuntti T, Fazekas F, Ferro JM, Langhorne P, O'Brien J, Scheltens P, Visser MC, Wahlund LO, Waldemar G, Wallin A, Hennerici MG; LADIS study group. Association of gait and balance disorders with age-related white matter changes: the LADIS study. Neurology. 2008;70(12):935-42. doi:https://doi. org/10.1212/01.wnl.0000305959.46197.e6. [PubMed] [Google Scholar].

35. Hugenschmidt CE, Burdette JH, Morgan AR, Williamson JD, Kritchevsky SB, Laurienti PJ. Graph theory analysis of functional brain networks and mobility disability in older adults. J Gerontol A Biol Sci Med Sci. 2014;69(11):1399406. doi:https://doi.org/10.1093/gerona/glu048. [PubMed] [Google Scholar].

\section{Submit your next manuscript to BioMed Central and we will help you at every step:}

- We accept pre-submission inquiries

- Our selector tool helps you to find the most relevant journal

- We provide round the clock customer support

- Convenient online submission

- Thorough peer review

- Inclusion in PubMed and all major indexing services

- Maximum visibility for your research

Submit your manuscript at www.biomedcentral.com/submit 